\title{
ARTIGO
}

\section{Trabalho e Saúde Emocional em tempos de COVID-19}

\author{
Work and Emotional Health in COVID-19 times
}

\section{Valdete Souto Severo, D.Sc.}

Doutora em Direito do Trabalho pela USP/SP, pós doutoranda em Ciências Políticas pela UFRGS/RS, professora, coordenadora do Grupo de Pesquisa Trabalho e Capital da UFRGS/RS; juíza do trabalho, membra do RENAPEDTS - Rede Nacional de Pesquisa em Direito do Trabalho e Seguridade Social, Presidenta da AJD Associação Juízes para a Democracia; membra da diretoria da ALTJ Associação Latinoamericana de Jueces del Trabajo.

\section{Isabela Pimentel de Barros, M.Sc.}

Mestranda em Direito do Trabalho pela UERJ, pós graduada em Direito do Trabalho e Processo do Trabalho, advogada, membra efetiva do Instituto dos Advogados Brasileiros (IAB), Diretora da Associação Carioca dos Advogados Trabalhistas (ACAT- 2019- 2021), membra da Comissão Especial de Direito Sindical da OAB/RJ.

RESUMO: Os fatores psicossociais trazem inúmeras consequências para a saúde e segurança do trabalhador, bem como para o mundo do trabalho. Além de difícil reconhecimento como doença ocupacional ou como acidente de trabalho, as doenças psíquicas não se relacionam somente com doenças como estresse e depressão, mas também com inúmeras outras como, a título de exemplo, as doenças cardiovasculares ou musculares, vez que os riscos psicossociais estão estreitamente relacionados ao estresse laboral. Apesar de ser um assunto extremamente relevante para a saúde pública e para a sociedade como um todo, o Direito do Trabalho pouco se ocupa com o seu estudo. Nesse sentido, em um primeiro momento, buscamos esclarecer ao leitor as principais medidas realizadas pelas reformas trabalhistas espanhola (2012) e brasileira (2017) para, após, analisar as consequências concretas das mesmas em termos de desemprego, desalento e afastamento do trabalho por doenças nesses dois países. Em seguida, indicaremos as medidas adotadas por esses países diante da realidade da pandemia da COVID-19 e discutiremos as suas eficiências como medida de estabilização social e cuidado com a saúde e a vida de quem depende do trabalho para sobreviver. Restou demonstrado o expressivo aumento do número de pessoas acometidas de doenças psíquicas em razão do trabalho, o que tende a agravar-se com a crise econômica instaurada, com o desemprego massivo, com as opções legislativas

Laborare. Ano III, Número 5, Jul-Dez/2020, pp. 45-68. ISSN 2595-847X. https://revistalaborare.org/ DOI: https://doi.org/10.33637/2595-847x.2020-57 
que priorizam o capital em detrimento de quem vende a sua força de trabalho e com a política adotada pelo Brasil em meio a mais de 140 mil mortos.

Palavras-chave: saúde mental, riscos psicossociais, doenças ocupacionais, reformas trabalhistas, pandemia do Covid-19.

ABSTRACT: Psychosocial factors have numerous consequences for the health and safety of workers, as well as for the world of work. In addition to being difficult to recognize as an occupational disease or an accident at work, mental illnesses are not only related to illnesses such as stress and depression, but also countless other illnesses, such as cardiovascular or muscle diseases, as the risks psychosocial problems are closely related to work stress. Despite being an extremely relevant subject for public health and for society as a whole, labor law has little to do with its study. In this sense, at first, we seek to clarify to the reader the main measures taken by the Spanish (2012) and Brazilian (2017) labor reforms, after which to analyze their concrete consequences in terms of unemployment, discouragement and sick leave from work in these two countries. Then, we will indicate the measures adopted by these countries in the face of the reality of the COVID-19 pandemic and discuss their efficiencies as a measure of social stabilization and care for the health and life of those who depend on work to survive. It remained to be demonstrated the expressive increase in the number of people suffering from mental illnesses due to work, which tends to worsen with the economic crisis established, with massive unemployment, with the legislative options that prioritize capital to the detriment of those who sells its workforce and with policy that Brazil has in the midst of more than 140 thousand deaths.

Keywords: mental health, psychosocial risks, occupational diseases, labor reforms, Covid-19 pandemic.

\section{INTRODUÇÃO}

“(...) Pai, afasta de mim esse cálice De vinho tinto de sangue Como beber dessa bebida amarga Tragar a dor, engolir a labuta Mesmo calada a boca, resta o peito Silêncio na cidade não se escuta De que me vale ser filho da santa Melhor seria ser filho da outra Outra realidade menos morta

Laborare. Ano III, Número 5, Jul-Dez/2020, pp. 45-68. ISSN 2595-847X. https://revistalaborare.org/ DOI: https://doi.org/10.33637/2595-847x.2020-57 
Tanta mentira, tanta força bruta

Como é difícil acordar calado

Se na calada da noite eu me dano

Quero lançar um grito desumano

Que é uma maneira de ser escutado

Esse silêncio todo me atordoa

Atordoado eu permaneço atento

Na arquibancada pra a qualquer momento

Ver emergir o monstro da lagoa

De muito gorda a porca já não anda

De muito usada a faca já não corta

Como é dificil, pai, abrir a porta

Essa palavra presa na garganta(...)"

(Cálice, Chico Buarque, 1973)

Composta em 1973 por Chico Buarque, em um período em que a censura não permitia que a verdade fosse dita, "Cálice" denuncia as mortes, a repressão, os horrores da Ditadura civil-empresarial-militar, a opção política que foi responsável pela morte e pela tortura de mais de 20 (vinte) mil pessoas. Passadas três décadas da abertura democrática, já são mais de 140.000 mortos pela doença causada pelo novo coronavírus (COVID-19, na sigla em inglês), além de um número absurdo de registros de morte por Síndrome Respiratória Aguda Grave, isso sem contar os inúmeros mortos que, por falta de atendimento ou testagem, faleceram sem contar nas estatísticas. Ou aqueles que faleceram por outras doenças, em razão da falta de atendimento médico adequado. Já são mais de 4 milhões de pessoas contaminadas. Ao mesmo tempo, atingimos um nível recorde de desocupação e de desigualdade. Ainda assim, vimos um Presidente da República que se negou a reconhecer a gravidade da Pandemia e o Parlamento aprovou leis que retiram ainda mais direitos trabalhistas. As populações indígenas estão sendo dizimadas pela ausência de acesso a atendimento médico ou controle da disseminação do vírus. Nossas reservas naturais estão sendo saqueadas, empresas públicas estão sendo privatizadas.

Cálice é "cale-se", o silenciamento diante do sangue derramado. Também hoje há censura: juízes, professores e policiais que ousam criticar a política atual estão sendo perseguidos e silenciados. A pandemia provocada pelo Novo Coronavírus da Síndrome Respiratória Aguda (SARS-Cov2, da sigla em inglês) encontra uma população desamparada por "reformas" e políticas que privilegiam poucos em detrimento da maioria. A música revela-se assustadoramente atual. Por que beber dessa bebida amarga, tragar a dor, engolir a labuta, se ainda resta o peito, o sofrimento, a dor individual e coletiva de uma sociedade que está em luto? Os efeitos da desconstrução das regras de proteção social somadas à pandemia são devastadores, também da perspectiva emocional, especialmente para quem vive do trabalho. A vontade de Chico Buarque, de lançar um grito desumano, arranjar uma maneira de ser

Laborare. Ano III, Número 5, Jul-Dez/2020, pp. 45-68. ISSN 2595-847X. https://revistalaborare.org/ DOI: https://doi.org/10.33637/2595-847x.2020-57 
escutado, é o que move a muitos de nós. O silêncio que atordoa diante da ausência de equipamentos de proteção individual, das despedidas coletivas, das propostas legislativas cada vez mais hostis à classe trabalhadora, entristece e adoece. Quem trabalha na área de saúde e em trabalhos vulneráveis, com a saúde ameaçada constantemente; quem se expõe de modo cotidiano como as diaristas, os terceirizados, os entregadores de aplicativos, assim como os falsos autônomos; quem precisou se adaptar, inclusive economicamente, à realização de teletrabalho: todas essas pessoas têm a sensação diária da vida social interrompida, do medo da morte, do estresse, do desamparo e da insegurança em relação ao futuro.

Este artigo tem por objetivo investigar o expressivo aumento do número de pessoas acometidas de doenças psíquicas em razão do trabalho e sua relação com as chamadas "reformas", com a precarização nas condições de vida, tanto no Brasil quanto na Espanha, bem como com a pandemia da COVID-19. A insegurança de um trabalho temporário, intermitente ou terceirizado, a subremuneração, a alta rotatividade e assim como a dificuldade em encontrar um emprego, somam-se à imposição de teletrabalho, redução de salário ou suspensão de contrato autorizadas em razão da pandemia, e criam um ambiente psiquicamente adoecedor. Isso porque a maioria das pessoas não tem condições de escolher o trabalho que realiza, sua intensidade ou o número de horas do dia em que precisará estar à disposição de quem se apropria da sua força de trabalho. Há, ainda, o fato de que nas sociedades que, como a nossa, baseiam-se na troca, o desemprego é uma realidade estrutural. Portanto, quem depende do trabalho para sobreviver, temerá sempre a perda do emprego.

A perspectiva que aqui se adota é a de que o adoecimento não é algo que afeta apenas a vida de quem trabalha. Há um custo social, que decorre da necessidade de tratamento, atendimento médico, utilização de remédios, que oneram o sistema de previdência social. Portanto, a lógica de precarizar ainda mais as condições de trabalho se traduz como econômica e socialmente destituída de fundamento.

Neste artigo, apresentaremos as principais alterações que resultaram das "reformas" ocorridas na Espanha e no Brasil, bem como suas consequências concretas em termos de desemprego, desalento e afastamento do trabalho por doença, nesses dois países. Em seguida, indicaremos as medidas adotadas por esses países diante da realidade da pandemia da COVID-19 e discutiremos a sua oportunidade e eficiência como forma de estabilização social e cuidado com a saúde e a vida de quem depende do trabalho para sobreviver.

Laborare. Ano III, Número 5, Jul-Dez/2020, pp. 45-68. ISSN 2595-847X. https://revistalaborare.org/ DOI: https://doi.org/10.33637/2595-847x.2020-57 


\section{AS REFORMAS TRABALHISTAS NO BRASIL E NA ESPANHA}

No Brasil, as principais alterações ocorreram a partir de 2016. A Emenda Constitucional (EC) 95, aprovada em dezembro de 2016, determinou o congelamento das despesas com saúde, educação, moradia e trabalho por 20 anos. Apenas durante o ano de 2019, esse contingenciamento de gastos resultou na perda de $\mathrm{R} \$ 20$ bilhões em investimento na área da saúde.

As Leis n. ${ }^{\circ} 13.429$ e 13.467, ambas de 2017, alteraram mais de 200 dispositivos da Consolidação das Leis do Trabalho (CLT) e a lei do trabalho temporário, ampliando as possibilidades de terceirização ${ }^{2}$, criando contratos precários, facilitando a dispensa e a majoração da jornada, retirando o caráter remuneratório de algumas verbas, fragilizando as possibilidades de atuação dos sindicatos, entre outras alterações.

A apelidada "reforma" (Lei n. ${ }^{\circ}$ 13.467) prejudica fortemente a atuação sindical, introduz a possibilidade de acordo individual para realização e jornada regular de $12 \mathrm{~h}$, sem intervalo e com possibilidade de extensão desse tempo de trabalho. A Medida Provisória (MP) n. ${ }^{\circ}$ 927/2020 reforça a possibilidade de realização de jornadas de mais de 12 horas, mediante acordo individual, exatamente para os trabalhadores da área da saúde. Essa lei ainda facilita a despedida, fragiliza a remuneração e altera vários dispositivos processuais, dificultando o acesso à justiça. Altera dispositivos da Lei n. $^{\circ}$ 13.429/2017 para permitir que todas as atividades de uma empresa sejam terceirizadas.

A "reforma" ainda criou a modalidade de trabalho intermitente, um contrato em que não há dever de oferta de trabalho. A lei ainda obriga a mulher gestante ou lactante a levar atestado médico para a empresa, a fim de que seja afastada do ambiente insalubre de trabalho, colocando-a em situação de extrema fragilidade diante do empregador.

A Lei n. ${ }^{\circ} 13.874$ de 2019 está dentro do bojo de reformas legislativas que afetam o mundo do trabalho não apenas por seu aspecto simbólico, mas também porque o artigo 15 dessa lei altera vários dispositivos da CLT. Entre outras coisas, aumenta o prazo para o registro do vínculo de emprego na carteira de trabalho e altera o $\S 2^{\circ}$ do art. 74 da CLT, dispositivo que fixa o dever de registro escrito da jornada de trabalho. A alteração é para dispor que esse dever se aplica apenas para "os estabelecimentos com mais de 20 (vinte) trabalhadores". Ainda, cria a possibilidade de "registro de ponto por exceção à jornada regular de trabalho".

Laborare. Ano III, Número 5, Jul-Dez/2020, pp. 45-68. ISSN 2595-847X. https://revistalaborare.org/ DOI: https://doi.org/10.33637/2595-847x.2020-57 
Também faz parte do pacote de alterações na legislação social, a chamada "reforma" da previdência. As alterações inseridas no texto constitucional pela EC 103/2019 tornaram necessário que a(o) trabalhador(a) brasileiro(a) contribua pelo tempo mínimo de 20 anos se homem e 15 se mulher, para que possa obter aposentadoria com renda igual a $60 \%$ da média de todos os salários de contribuição, assegurado o salário mínimo. A forma de cálculo faz com que praticamente todos os aposentados recebam apenas o mínimo. A aposentadoria integral é obtida apenas após a mulher trabalhadora contribuir por 35 anos e o homem, por 40 anos. Deverá, também, ser observada a idade mínima de 62 e 65 anos, respectivamente. Ou seja, na prática ficará quase impossível obter aposentadoria no Brasil.

Em 2020, em plena pandemia, o governo federal ainda editou as MP n. ${ }^{\circ} 927$ e 936 . A primeira perdeu vigência, mas a segunda (MP 936) já foi aprovada nas duas casas do Congresso Nacional e sancionada (Lei n. ${ }^{\circ}$ 14.020). Essa lei autoriza redução de salário e jornada, por acordo individual, oferecendo em troca um valor indenizatório, irrisório, de complementação emergencial de renda. Sob o argumento de que com isso o governo evitaria o desemprego, a lei autoriza a perda de até $70 \%$ do salário, por meio de acordo individual, ou suspensão completa do pagamento, enquanto durar a pandemia, de modo que o vínculo se mantenha, mas a renda não. Mesmo assim, o Brasil atingiu nos últimos meses o recorde em número de pessoas desempregadas e de pessoas que simplesmente pararam de procurar emprego. Pela primeira vez desde que esse índice é considerado, o Brasil tem mais pessoas economicamente ativas (PEA) desempregadas do que contratadas. São 88 milhões de adultos sem emprego e 86 milhões empregados. A taxa oficial de desemprego subiu para $12,9 \%$ no trimestre encerrado em maio/2020, atingindo 12,7 milhões de pessoas. Foi registrado um fechamento de 7,8 milhões de postos de trabalho em relação ao trimestre anterior (IBGE, 2020).

Até o dia 29 de junho o Ministério da Justiça havia registrado acordos de redução de salário envolvendo 11.698.243 de trabalhadoras e trabalhadores. Pessoas que estão certamente contingenciando gastos básicos com alimentação e vestimenta, quando não contraindo empréstimos bancários para dar conta das despesas ordinárias. Não há como desconhecer, porém, que mesmo para quem tem a possibilidade de se isolar, permanecer em casa traz, como consequência imediata, aumento de gastos ordinários com alimentação, água, luz. Para quem tem a possibilidade de realizar o teletrabalho, pode também implicar mais gastos com internet. Nesse contexto, torna-se ainda mais ilógico promover redução de salário, pouco importando que isso ocorra através de acordo individual ou norma coletiva.

Laborare. Ano III, Número 5, Jul-Dez/2020, pp. 45-68. ISSN 2595-847X. https://revistalaborare.org/ DOI: https://doi.org/10.33637/2595-847x.2020-57 
O resultado concreto dessas alterações legais é que além de não melhorar a competitividade ou gerar empregos, essas alterações promovem redução de consumo. O Produto Interno Bruto (PIB) caiu 9,7\% no segundo trimestre de 2020.

A Pesquisa Nacional por Amostra de Domicílio (PNAD) Contínua 2019 mostra que o rendimento do $1 \%$ de pessoas que ganha mais em nosso país equivale a 33,7 vezes o da metade da população que ganha menos. Enquanto o rendimento médio mensal de quem ganha mais com o trabalho é de $\mathrm{R} \$ 28.659,00$, o de quem ganha menos é de $\mathrm{R} \$$ 850,00 (IBGE, 2020, b).

Nos últimos dois anos, a taxa de desemprego não parou de subir, chegando ao assustador patamar de 13,7 milhões de pessoas desocupadas e um total de 27,9 milhões de pessoa subutilizadas, eufemismo para caracterizar o conjunto de pessoas que estão desocupadas, trabalham menos de 40 horas semanais ou "estão disponíveis para trabalhar, mas não conseguem procurar emprego por motivos diversos". Esse é o maior índice desde 2012. Diante de tal panorama, não é difícil intuir que o coeficiente de Gini, índice que mede a desigualdade de renda, só tem piorado no país. De igual sorte, não é difícil intuir o que tal situação causa na saúde de quem depende do trabalho para sobreviver.

$\mathrm{Na}$ Espanha, a Lei do Estatuto dos Trabalhadores (Ley del Estatuto de los Trabajadores- LET) foi criada em 1980 e, ademais das inúmeras modificações feitas, passou por duas grandes "reformas", sendo a relevante para o objeto deste artigo a realizada em 2012, que foi precedida de alterações realizadas em 2010. As "reformas" citadas foram propostas para o enfrentamento de crises econômicas pelas quais o país passava, sendo certo que se inseriram em um contexto de medidas de austeridade.

Em 2010, o Real Decreto Lei (RDL) n. ${ }^{\circ}$ 10/2010, convertido posteriormente na Lei n. ${ }^{\circ} 35 / 2010$, foi editado quando o país havia perdido, nos dois anos anteriores, mais de dois milhões de postos de trabalho e a taxa de desemprego estava próxima a $20 \%$. Tinha como objetivos principais, conforme a exposição de motivos, recuperar a criação de emprego e diminuir a taxa de desemprego, reduzindo a dualidade ${ }^{3}$ do mercado de trabalho através do estímulo à criação de empregos estáveis e de qualidade, reforçar os instrumentos de flexibilidade interna no desenvolvimento das relações trabalhistas e, ainda, privilegiar as medidas de redução de jornada, com mecanismos que permitissem a manutenção do emprego (ESPANHA, 2010).

A exposição de motivos da "reforma" ocorrida em 2012, informa que as alterações anteriores não deram certo, que a crise econômica vivida pela Espanha desde 2008 revelou

Laborare. Ano III, Número 5, Jul-Dez/2020, pp. 45-68. ISSN 2595-847X. https://revistalaborare.org/ DOI: https://doi.org/10.33637/2595-847x.2020-57 
debilidades do modelo trabalhista espanhol: o desemprego havia aumentado ainda mais, próximo a $22,85 \%$. Entre os menores de 25 anos, essa taxa se aproximava a 50\%. Logo, tinha-se a obrigação de garantir e satisfazer os interesses daqueles que buscavam um emprego e, por isso, a "reforma" tratava de garantir a flexibilidade dos empresários na gestão dos "recursos humanos", como segurança dos trabalhadores no emprego e adequados níveis de proteção social. Pregava-se, então, a flexissegurança. Comparada por muitos com a "reforma" ocorrida no Brasil em 2017, teve início através do RDL n. ${ }^{\circ}$ 03/2012 e se consolidou com a edição da Lei n. ${ }^{\circ}$ 03/2012 de 06 de julho de 2012.

De forma sintética, as principais alterações realizadas através das "reformas" de 2010 e 2012 na Espanha foram: a alteração do artigo que regulamenta o teletrabalho ${ }^{4}$; a redução ${ }^{5}$ da indenização para as chamadas demissões improcedentes ${ }^{6}$; a ampliação das chamadas causas objetivas para a dispensa. Passa a ser permitida a realização de horas extras nos contratos de trabalho por tempo parcial; há a regulamentação de a possibilidade de suspensão dos contratos por causas econômicas, técnicas, de organização, de produção ou por força maior ${ }^{7}$. Cria-se um novo tipo de contrato de apoio a empreendedores para pequenas e médias empresas que possuam menos de 50 (cinquenta) empregados (ESPANHA, 2012).

Em termos de direito coletivo, as alterações, tal como ocorreu no Brasil em 2017, foram relevantes, tendo sido as principais a eliminação do requisito da autorização administrativa para as demissões coletivas e o fim da ultratividade.

É importante notar que as alterações promovidas na legislação trabalhista espanhola em 2012 têm inúmeras coincidências com as medidas introduzidas com a chamada "reforma" brasileira (Lei n. ${ }^{\circ}$ 13.467). Sabemos, com base nos resultados da "reforma" espanhola, que adotarmos medidas semelhantes implicaria resultados semelhantes, que beneficiam apenas quem detém capital. A respeito deste assunto, importante destacar o estudo que, a partir da análise dos efeitos das "reformas" trabalhistas realizadas em 111 (cento e onze) países entre os anos de 2008 e 2014, demonstrou que a desregulamentação dos direitos trabalhistas, seja em países desenvolvidos, seja nos países em desenvolvimento, está associada a queda na taxa de empregos no ano seguinte, comprovando os efeitos negativos das reformas desregulatórias do mercado de trabalho (ADASCATELI; MORANO, 2015, p.13).

Em 2019, no relatório intitulado "World Employment Social Outlook", a Organização Internacional do Trabalho (OIT) alertou para a precarização do emprego mundial. No mesmo documento, a OIT chama a atenção que a Espanha possuía, ao final de 2017, uma taxa de temporalidade de emprego de $26,8 \%$, sendo certo que os contratos de trabalho temporário com duração de seis meses ou menos representavam mais da

Laborare. Ano III, Número 5, Jul-Dez/2020, pp. 45-68. ISSN 2595-847X. https://revistalaborare.org/ DOI: https://doi.org/10.33637/2595-847x.2020-57 
metade de todos os contratos temporários no país e, aproximadamente, $85 \%$ deles estavam empregados em um contrato temporário por não conseguirem um emprego melhor. Ademais, os trabalhadores a tempo parcial e temporário costumam ter um salário mais baixo, perto da linha de pobreza relativa, inferiores a $60 \%$ (sessenta por cento) da renda média (OIT, 2019).

No final do ano de 2019, a taxa de desemprego na Espanha estava, aproximadamente, em 14\% e, embora ainda alta, lembramos que, no auge da crise econômica, essa taxa chegou a ultrapassar $20 \%$, mas os dados acima citados demonstram que a recuperação dos empregos na Espanha não está relacionada à empregabilidade com qualidade, mas sim a empregos precários (INE, 2020, a).

Assim, quando a pandemia da COVID-19 alcançou a Espanha, o PIB do país vinha crescendo ininterruptamente por seis anos e, em que pese tivesse uma taxa menor de desemprego, isso se baseava, em boa parte, em contratos precários. A Espanha ainda se situa entre um dos países mais desiguais da Europa, embora seu índice de Gini seja consideravelmente melhor que o do Brasil. $\mathrm{O}$ rendimento médio por pessoa aumentou em $2,3 \%$ em relação ao ano anterior. A população em risco de pobreza ou exclusão social (taxa AROPE) ficou em 25,3\% em relação ao $26,1 \%$ no ano anterior. O indicador income quintile ratio indicava que, em 2018, os $20 \%$ mais ricos contavam com uma renda seis vezes maior que os $20 \%$ mais pobres. Aproximadamente $21,5 \%$ da população estava em Risco de Pobreza em 2018 e em que pese o PIB estivesse aumentando desde 2014, a taxa de pobreza foi reduzida em $0,7 \%$, demonstrando que o crescimento econômico, por si só, não traz a redução da pobreza. Além disso, desde 2014, a taxa de pobreza entre as pessoas com trabalho se mantém em torno de $14 \%$, ratificando que não é qualquer trabalho que protege da pobreza (INE, 2019).

Assim como no Brasil, a Espanha declarou estado de emergência ${ }^{8}$ (Real Decreto n. ${ }^{\circ}$ 463/2020), em 14 de março, em razão da pandemia, e impôs inúmeras medidas restritivas de circulação, impactando o mundo do trabalho. O Real Decreto Lei n. ${ }^{\circ}$ 8/2020, de 17 de março, dispôs sobre a necessidade de priorizar mecanismos alternativos que garantissem a continuidade da atividade comercial e das relações de trabalho, particularmente através de trabalho remoto. O governo espanhol lançou um programa de financiamento, ativando doações e créditos para pequenas e médias empresas. Foi disposto, ainda, o direito de comprovar os deveres de cuidar de dependentes devido a circunstâncias excepcionais relacionadas à prevenção da extensão da COVID-19, para obter adaptação ou redução do horário de trabalho, com a consequente redução proporcional do salário. Foi prevista, ainda, a possibilidade de suspensão contratual e redução da jornada, quando a necessidade de utilizar tais

Laborare. Ano III, Número 5, Jul-Dez/2020, pp. 45-68. ISSN 2595-847X. https://revistalaborare.org/ DOI: https://doi.org/10.33637/2595-847x.2020-57 
mecanismos tiver causa direta com as consequências da COVID-19, sendo considerada decorrente de situação de força maior (ESPANHA, 2020).

O Real Decreto Lei n. ${ }^{\circ}$ 09/2020, de 27 de março, esclarece, no entanto, que a força maior, as causas econômicas, de organização, de produção e técnicas nas quais se amparam as possibilidades de suspensão e redução de jornada dos contratos não serão consideradas como causas de extinção do contrato, impedindo, na prática, as demissões nesse período uma vez que tais causas seriam consideradas como motivos "justos" para a ocorrência de dispensas, razão da importância dessa previsão legal (ESPANHA, 2020).

O Real Decreto Lei n. ${ }^{\circ}$ 10/2020, de 29 de março, por sua vez, estabeleceu uma espécie de licença remunerada para os empregados que não trabalhem em serviços considerados como essenciais e não tenham a possibilidade de trabalhar remotamente. Segundo o decreto, os trabalhadores continuarão recebendo seus salários e complementos salariais e, posteriormente, após o fim do estado de emergência, deverão compensar as horas não trabalhadas, o que será estipulado através de acordo a ser realizado entre a empresa e o representante dos trabalhadores. O Real Decreto Lei n. ${ }^{\circ} 11 / 2020$, de 31 de março, estabeleceu alguns subsídios para os autônomos como, por exemplo, a postergação do pagamento de suas cotas previdenciárias, o recebimento do equivalente a prestação de seguro desemprego para o autônomo que tenha perdido, no mínimo, $75 \%$ de seu faturamento e, desde que esteja em dia com as contribuições previdenciárias ${ }^{9}$, a postergação do pagamento de hipoteca e de alugueres para estabelecimentos comerciais (ESPANHA, 2020).

Alguns dados divulgados recentemente pelo Instituto Nacional de Estadística (INE) merecem ser citados para reflexão: 66,1\% dos negócios continuaram abertos e, aproximadamente, $2 / 3$ deles reduziram as suas vendas; quase $70 \%$ das empresas tiveram que reorganizar ou reduzir a jornada; cerca de $40 \%$ das empresas adotaram o chamado Expediente de Regulación Temporal de Empleo (ERTE); 48,8\% das empresas utilizaram o teletrabalho para manter o nível de atividade, sendo que $1 / 3$ dos estabelecimentos que o adotaram declaram que irão mantê-lo no futuro, enquanto $40,8 \%$ das empresas declararam não ter feito nenhuma modificação na sua forma de trabalhar (INE, 2020, b).

Quando analisamos os dados relativos ao desemprego, percebemos que as medidas, tal como no Brasil, foram insuficientes. Dados demonstram uma taxa de desemprego ascendente que, no segundo trimestre de 2020 estava em $15,33 \%$, sendo que o número de pessoas ocupadas diminuiu em 1.074.000, em relação ao trimestre anterior e houve um decréscimo de $22,59 \%$ em relação às horas trabalhadas (INE, 2020, c).

Laborare. Ano III, Número 5, Jul-Dez/2020, pp. 45-68. ISSN 2595-847X. https://revistalaborare.org/ DOI: https://doi.org/10.33637/2595-847x.2020-57 
O RDL n. ${ }^{\circ} 19 / 2020$, de 26 de maio, em seu artigo $9^{\circ}$ reconhece como acidente de trabalho as doenças sofridas pelos trabalhadores que prestam serviços nos centros de saúde ou sociais, em consequência do contágio do vírus SARS-CoV2 durante o estado de emergência (ESPANHA, 2020).

Por fim, cabe adicionar o Real Decreto Lei n. ${ }^{\circ}$ 20/2020, de 29 de maio, que criou a renda mínima vital a fim de auxiliar os vulneráveis economicamente, bem como reduzir a pobreza e a desigualdade no país. Tem previsão de um pagamento mensal máximo entre 462 e 1.015 euros, dependendo do tipo de família. Curioso notar que, na justificativa desse Real Decreto, é reconhecida a enorme desigualdade que, claro, foi agravada pela pandemia, bem como sua consequência para o incremento da vulnerabilidade econômica e social (ESPANHA, 2020).

\section{ALGUNS DADOS SOBRE A SAÚDE MENTAL DA CLASSE TRABALHADORA NO BRASIL E NA ESPANHA ANTES E APÓS AS "REFORMAS"}

Para a análise, ainda que superficial, que aqui nos propomos, buscamos avaliar os fatores psicossociais de risco apontados no ano de 2011, ano em que a Espanha passava por uma grave crise econômica e já havia, inclusive, enfrentado uma primeira "reforma" em 2010, e o ano de 2015, ano em que o país já estava se recuperando economicamente da crise iniciada em 2008 e ainda não enfrentava a crise econômica mundial originada pela pandemia da COVID-19.

Em 2011, na pesquisa nacional realizada na Espanha, quanto aos fatores de risco psicossociais, abordou três aspectos: as exigências que devem ser atendidas no trabalho, o grau de autonomia para decidir como executar a tarefa e as relações sociais no trabalho, analisadas através do nível de apoio, o reconhecimento do trabalho e as situações de violência sofridas. No que tange às exigências do trabalho, $23,9 \%$ relataram que se sentem muito cansados ou esgotados, $46 \%$ consideram que devem trabalhar muito rápido, $45,3 \%$ devem atender várias tarefas ao mesmo tempo e $34,9 \%$ indicaram que devem trabalhar com prazos muito curtos. $20,7 \%$ indicaram que devem atender a essas três últimas exigências simultaneamente. Mais de $20 \%$ consideraram que devem realizar tarefas complexas, complicadas ou muito difíceis e $64 \%$ devem tratar diretamente com pessoas que não estão empregadas. Entre $20 \%$ e $35 \%$ dos trabalhadores não tem a possibilidade de eleger ou modificar o método e o ritmo de trabalho, a ordem das tarefas ou, ainda, colocar em prática suas próprias ideias. Se apenas $7,3 \%$ têm a percepção de não poder contar com o apoio dos colegas de trabalho, $16,9 \%$ apontam que não podem contar com os seus chefes. Quanto aos tipos de violência, $11 \%$ declaram ter sofrido alguma no ambiente de trabalho, sendo

Laborare. Ano III, Número 5, Jul-Dez/2020, pp. 45-68. ISSN 2595-847X. https://revistalaborare.org/ DOI: https://doi.org/10.33637/2595-847x.2020-57 
as mais relatadas: a) as agressões verbais, rumores ou isolamento social, b) ameaças de violência física, c) violência física cometida por pessoas que não pertencem ao seu local de trabalho (ESPANHA, 2017, 2018).

Entende-se, desta forma, que a duração e a organização do tempo de trabalho afetam diretamente o nível de esforço e de fadiga produzidos pela atividade laboral, influenciando, ainda que indiretamente, o grau de exposição a riscos laborais. A média de horas trabalhadas por semana é de 38,5 horas, sendo que os homens trabalham de forma remunerada mais horas que as mulheres. $32,2 \%$ trabalham aos sábados e 16,7\% aos domingos, sendo que, em média, $40 \%$ dos trabalhadores assinalaram que ultrapassam a sua jornada habitualmente. Em média, um de cada quatro empregados $(22,6 \%)$ manifesta dificuldades para conciliar seu horário de trabalho com a vida pessoal e familiar.

Um dado relevante consiste no fato de que as exposições no trabalho são a quarta causa de câncer na Espanha, estando atrás apenas do tabaco, da alimentação e do sedentarismo. Se de 1964 a 2011 foram reconhecidos, no total, 340 cânceres profissionais na Espanha, os anos entre 2008 e 2011, foram responsáveis por 68\% dos casos registrados. No ano de 2011, ocorreram 581.150 acidentes de trabalho com licença médica na Espanha, sendo relevante destacar que, dos acidentes mortais, destacaram-se os infartos, derrames cerebrais e outras patologias não traumáticas. Em termos de doenças profissionais, foram registradas 19.195 enfermidades profissionais e 11.067 patologias não traumáticas causadas pelo trabalho. Embora a maior parte corresponda às doenças locomotoras, sem contabilizar as doenças agravadas pelo trabalho, 103 foram endócrinas, 137 mentais, 693 relacionados ao sistema nervoso central e periférico e 1.629 foram enfermidades que afetam um dos cinco sentidos.

Quando observamos os dados de 2015, constata-se, quanto às percepções dos próprios trabalhadores, que $33 \%$ dos ativos consideram que devem trabalhar "sempre ou quase sempre" em uma grande velocidade e $35 \%$ consideram que devem cumprir tarefas em prazos muito curtos. Mais de $25 \%$ dos trabalhadores consideram que devem cumprir ambas as exigências: trabalhar em uma grande velocidade e com prazos curtos. Aproximadamente $70 \%$ dos trabalhadores que sempre ou quase sempre lidam com pessoas que não são empregados onde trabalham como, por exemplo, clientes, enfrentam, por pelo menos $25 \%$ de seu tempo, pessoas irritadas, o que pode gerar um ambiente de trabalho desfavorável. Se em 2011, 23,9\% dos trabalhadores sentiam-se esgotados por terem muito trabalho, esse percentual ascende para $28 \%$ em 2015 (ESPANHA, 2011; ESPANHA, 2013 e ESPANHA, 2017).

Laborare. Ano III, Número 5, Jul-Dez/2020, pp. 45-68. ISSN 2595-847X. https://revistalaborare.org/ DOI: https://doi.org/10.33637/2595-847x.2020-57 
Chama a atenção o fato de que, em 2015, na média, 4,9\% dos trabalhadores sofrerem algum tipo de discriminação, representando um acréscimo significativo em relação a 2005, quando era de 2\%. Enquanto, em 2015, na Espanha, os homens trabalhavam de forma remunerada uma média de 39,7 horas semanais, as mulheres trabalhavam 33,9 horas, sendo certo que estas dedicavam, em média, 13 horas a mais que os homens ao trabalho de cuidado não remunerado. Quanto ao trabalho aos sábados e domingos, também há um acréscimo em relação a 2011: 54\% trabalham aos sábados e 33\% aos domingos.

Quase 1/3 dos trabalhadores informou que, no último ano, perdeu algum dia de trabalho em razão de uma licença médica ou por motivos de saúde, porcentagem semelhante a apontada em 2010. A cada 100 dias de licença médica no ano, 22 dias seriam decorrentes de acidente de trabalho e 32 , de problemas de saúde relacionados ou agravados pelo trabalho. Todavia, $41 \%$ dos trabalhadores afirmaram ter trabalhado doente no último ano, sendo tal porcentagem superior a 2010 , quando $35 \%$ dos trabalhadores afirmaram a mesma coisa. Indagados sobre a frequência com que estavam submetidos a situações de estresse no trabalho, 36\% dos entrevistados afirmaram "às vezes" e $30 \%$ que "sempre" ou "quase sempre", sendo esta porcentagem também superior a 2010, quando $23 \%$ das respostas indicavam submissão a tal situação. Por outro, lado quando os trabalhadores foram indagados sobre as suas percepções a respeito de seu estado de saúde, enquanto em 2011, 63,2\% achavam que apresentavam um bom estado de saúde, esse número cai para 55\% em 2015.

Quanto aos acidentes de trabalho, foram registrados 529.248, representando um decréscimo em relação a 2011. Foram registrados, em 2015, 19.138 processos de doenças profissionais, mantendo praticamente o número de 2011 e havendo um significativo decréscimo do número de patologias não traumáticas sofridas.

Em 2015, a Fiscalização, chamada na Espanha de "Inspección de Trabajo y Seguridad Social", emitiu um total de 96.393 ordens de serviço, na qual foram realizadas 69.928 visitas. Essas visitas resultaram 15.483 infrações, das quais 5,35\% estavam relacionadas aos fatores de riscos psicossociais. Em 2011, foram realizadas 79.276 visitas em matéria de prevenção de riscos laborais, as quais resultaram 19.900 infrações, sendo $4,72 \%$ relativas aos riscos ergonômicos e psicossociais. Constata-se, portanto, que, apesar de, em 2015, ter havido um menor número de atuações da inspeção do trabalho, as infrações quanto aos riscos psicossociais subiram, ainda mais se considerarmos que os dados de 2011 se referem aos fatores psicossociais e ergonômicos e os de 2015 somente aos psicossociais.

Quando se analisam, todavia, os anos de 2018 e 2019, seja no que tange aos acidentes de trabalho, seja no que tange às doenças profissionais, há um acréscimo relevante

Laborare. Ano III, Número 5, Jul-Dez/2020, pp. 45-68. ISSN 2595-847X. https://revistalaborare.org/ DOI: https://doi.org/10.33637/2595-847x.2020-57 
dos números: em 2018, foram 24.082 enfermidades profissionais e, em 2019, 27.292. Já quanto aos acidentes de trabalho, foram registrados 617.488 acidentes em 2018 e 650.602 em 2019 (ESPANHA, 2019).

No Brasil, tendo em vista que a "reforma" ocorreu em 2017, foram pesquisados dados anteriores e posteriores a este ano para fins de análise. Em 2015, foram reconhecidos pelo Instituto Nacional de Seguridade Social (INSS) 622.379 acidentes de trabalho e 15.386 doenças do trabalho. Ambas estatísticas apresentam um decréscimo no ano de 2017 (BRASIL, 2017), em que registrados 549.505 acidentes e 9.700 doenças do trabalho. Tais registros, entretanto, estão comprometidos em razão da subnotificação, cuja estimativa oficial é de que seja de pelo menos $20 \%$ (BRASIL, 2020, a). Os dados são aqui transcritos apenas para lançar luz na circunstância de que, ainda assim, os números relativos à depressão, transtornos de ansiedade, reações ao estresse, que são doenças imediatamente relacionadas aos fatores psíquicos, pouco se alteraram nos anos de 2015 e 2017. Logo, presente a subnotificação cada vez mais elevada, trata-se de uma constatação relevante para que se perceba o sensível aumento do adoecimento psicossocial ocasionado pelas condições de trabalho.

De acordo com a Agência Brasil, entre 2013 e 2017, transtornos mentais e comportamentais foram a terceira maior causa de afastamento dos trabalhadores brasileiros (AGÊNCIA BRASIL, 2017). Em 2018, a Organização Mundial de Saúde estimou que $10,3 \%$ da população teve a sua saúde deteriorada por algum distúrbio depressivo e 8,3\% por ansiedade (OMS, 2018). Já a Associação Nacional de Medicina do Trabalho aponta que 9 (nove) em cada 10 (dez) brasileiros no mercado de trabalho apresenta sintomas de ansiedade, do grau mais leve ao incapacitante e quase a metade (47\%) sofre de algum nível de depressão, recorrente em $14 \%$ dos casos e, com frequência, os doentes ficam mais de 100 (cem) dias afastados de suas funções. Dados do Observatório de Segurança e Saúde no Trabalho mostram que, em 2018, foram 623.800 acidentes de trabalho notificados, estimando-se uma subnotificação de $24,7 \%$ e um gasto previdenciário de mais de $\mathrm{R} \$ 6$ bilhões entre auxílio doença por acidente de trabalho e aposentadoria por invalidez decorrente de acidente de trabalho. De janeiro a março de 2019, foram aproximadamente 180 mil acidentes, o que significa dizer que ocorre em média um acidente de trabalho a cada 48 segundos, com uma morte a cada 3 horas. O observatório mostra, ainda, que os afastamentos por doenças mentais e comportamentais, conforme a Classificação Internacional de Doenças (CID) aumentaram de 4\% em 2012 para 9\% em 2018. Da mesma forma, as doenças nervosas aumentaram consideravelmente' já demonstrando os catastróficos resultados das reformas empreendidas (BRASIL, 2020, a).

Laborare. Ano III, Número 5, Jul-Dez/2020, pp. 45-68. ISSN 2595-847X. https://revistalaborare.org/ DOI: https://doi.org/10.33637/2595-847x.2020-57 
É preciso anotar a dificuldade na obtenção de dados em relação ao adoecimento em razão do trabalho no Brasil. A ausência de pesquisas oficiais específicas soma-se ao sucateamento dos órgãos de fiscalização, prevenção e notificação desse adoecimento.

\section{A PANDEMIA E O AGRAVAMENTO DOS RISCOS PSICOSSOCIAIS NO TRABALHO}

Países com grandes índices de desigualdade, como o Brasil, que nos últimos anos atuou concretamente para promover ainda mais miséria e exclusão social, através das já examinadas "reformas", encontram a pandemia de 2020 em situação de profundo desamparo. O Observatório do Terceiro Setor divulgou recentemente o aumento dos casos de síndrome de burnout no Brasil, em razão da "exaustão completa no trabalho, angústia para ir trabalhar e a impressão de que tudo que você produz é insatisfatório", o que acaba sendo potencializado por jornadas mais extensas, ausência de Equipamentos de Proteção Individuais (EPI), contratos precários, bem como pelo fato de que "o governo não tem tomado medidas efetivas para proteger as populações mais vulneráveis, como as pessoas da periferia, a população em situação de rua, e as comunidades indígenas, quilombolas e ribeirinhas" (OBSERVATÓRIO DO $3^{\circ}$ SETOR, 2020).

De acordo com o Boletim de Saúde Mental da Fundação Instituto Oswaldo Cruz (FIOCRUZ), os transtornos psíquicos imediatos mais frequentes, em razão da pandemia e do isolamento social, são os episódios depressivos e as reações de estresse agudo de tipo transitório. Há, também, referência ao potencial aumento do risco de surgimento destes transtornos, em razão de outros fatores de vulnerabilidade, ligados, inclusive, às condições de trabalho. O Boletim da FIOCRUZ aponta como principais efeitos tardios mais recorrentes o luto patológico, a depressão, os transtornos de adaptação, as manifestações de estresse pós-traumático, o abuso do álcool ou outras substâncias que causam dependência, além de transtornos psicossomáticos. Aponta, também, a recorrência de sintomas como o de tristeza, medo generalizado e ansiedade expressos corporalmente, em função do prolongamento do sofrimento que decorre da situação de pandemia (BRASIL, 2020, b).

Por ocasião do 01 de maio de 2020, o Conselho Regional de Psicologia do Paraná publicou nota sobre a importância da saúde mental durante a pandemia. Nela, ressalta que a proteção à saúde mental passa pela defesa da saúde pública e pela organização coletiva na luta por direitos humanos. A nota menciona exatamente o efeito nocivo das chamadas "reformas" trabalhistas, citadas no capítulo anterior, como circunstâncias que construíram um cenário de precarização, tornando-nos "mais vulneráveis em um contexto de recessão" como aquele aprofundado pela pandemia (CONSELHO REGIONAL DE PSICOLOGIA DO PARANÁ, 2020).

Laborare. Ano III, Número 5, Jul-Dez/2020, pp. 45-68. ISSN 2595-847X. https://revistalaborare.org/ DOI: https://doi.org/10.33637/2595-847x.2020-57 
A preocupação com a saúde mental e com o agravamento dos fatores psicossociais de adoecimento em razão do trabalho, durante a pandemia mundial, permeia também as declarações da Organização Mundial da Saúde (OMS). Já em maio deste ano, Tedros Adhanom Ghebreyesus, diretor-geral da OMS, referiu que: "O isolamento social, o medo de contágio e a perda de membros da família são agravados pelo sofrimento causado pela perda de renda e, muitas vezes, de emprego" (BRASIL, 2020, d), revelando o que aqui demonstramos. Há estreita ligação entre os efeitos que são inerentes à pandemia e o aprofundamento desses efeitos nocivos, na saúde psíquica de quem vive do trabalho, em países que, como o Brasil e a Espanha, promoveram recentemente amplo desmanche da regulação protetiva estatal do trabalho. Em documento publicado em 13 de maio, a OMS declarou que $70 \%$ da população que está na linha de frente do combate à pandemia, em trabalhos ligados à área da saúde, são mulheres. Observa que a pressão e o estresse que decorrem da exposição dos corpos, da percepção da morte e da impossibilidade de reação mais efetiva a uma doença ainda desconhecida exige que os líderes mundiais tenham atenção especial à saúde mental de quem trabalha, pois já está sendo apontado o aumento da ansiedade, dos afastamentos por estresse e depressão, entre os profissionais ligados à saúde (ONU, 2020).

A Organização Pan-Americana da Saúde lançou documento apontando a relação entre vulnerabilidade social e adoecimento psicossocial durante epidemias e aponta os principais grupos sociais atingidos: crianças, idosos, mulheres, populações indígenas, grupos minoritários, pessoas portadoras de deficiência, pessoas que já possuem problemas de ordem psicossocial. Aponta, também, a maior vulnerabilidade de quem vive na miséria, nas periferias das grandes cidades e os residentes ilegais. Cita os principais relatos de pessoas sobreviventes que passaram por situação de epidemia ou de eventos traumáticos que provocaram a morte de um número grande de pessoas: "pesar e aflição pela perda de familiares e amigos, que em certos casos coexistem com perdas materiais"; "perda da fé em Deus, perda do sentido da vida"; "temores de assumir novos papéis impostos pelo desaparecimento de um familiar"; "medos recorrentes de que possa ocorrer algo novamente ou que a morte vai ceifar outros familiares ou membros da comunidade"; medo da morte; "sentimentos de solidão e abandono"; "medo de esquecer ou ser esquecido"; raiva, culpa por ter sobrevivido, vergonha (ORGANIZAÇÃO PAN-AMERICANA DE SAÚDE, 2009).

É certo que a precarização das condições de trabalho aprofundou no Brasil uma realidade de desigualdade social que já era extremamente significativa.

A Organização para Cooperação e Desenvolvimento Econômico (OCDE) já aponta que o impacto econômico da COVID-19 é dez vezes maior que o observado nos primeiros meses da crise financeira global de 2008. Mesmo países que possuem uma

Laborare. Ano III, Número 5, Jul-Dez/2020, pp. 45-68. ISSN 2595-847X. https://revistalaborare.org/ DOI: https://doi.org/10.33637/2595-847x.2020-57 
rede de proteção social mais ajustada e se preocuparam em manter vínculos de emprego, restringindo despedidas e fazendo transferência de renda, estão sofrendo impactos econômicos, sociais e, consequentemente psíquicos. De acordo com projeções da OCDE, o desemprego deve aumentar para 9,4\% em média até o final de 2020. Se houver uma segunda onda da pandemia no final de 2020 , a taxa de desemprego aumentará ainda mais, podendo chegar a 12,6\% (OCDE, 2020).

A Espanha, apesar de haver promovido desmanche de direitos sociais nos últimos anos, adotou uma postura política de certo comprometimento com a contenção dos efeitos da COVID-19. Além de proibir demissões, ampliou o acesso a benefícios de seguro-desemprego, reduzindo ou renunciando totalmente aos requisitos de contribuição mínima e estendendo o benefício aos contratos de experiência, bem como aos trabalhadores que deixaram o emprego por uma nova oferta de trabalho que acabou atingida pela crise. Ainda assim, uma pesquisa realizada por uma empresa espanhola especializada em gestão de prevenção de riscos psicossociais, ao entrevistar 1.024 trabalhadores entre abril e junho deste ano, constatou que 41,99\% dos trabalhadores apresentaram sintomas de ansiedade e $27,3 \%$ sente que sua saúde piorou. Os relatos dos trabalhadores passam por várias queixas, entre elas, dor de cabeça, distúrbio de sono, dor no estômago e problema de memória, o que significa que, quase metade dos trabalhadores entrevistados, apresenta sintoma de depressão ou ansiedade (AFFOR, 2020). Além disso, a OCDE aponta que 56\% dos trabalhadores espanhóis estão em risco de contágio por COVID-19. Além disso, não se pode negar que as condições de vida da Espanha, embora ainda estejam longe de atingir o ideal, são bem superiores às do Brasil. Para se ter uma ideia, em 2019, a OMS aponta que o gasto por habitante com a saúde, na Espanha, em 2014, era de U\$ 2.966,00. Já no Brasil era de U\$ 1.318,00 (OMS, 2016).

O Brasil figura como um dos países com mais pessoas infectadas e fatalmente vitimadas pela doença. Desde que aqui chegou, em fevereiro de 2020, a COVID-19 já vitimou, pelos números oficiais, mais de 140.000 pessoas, até a conclusão deste artigo. O Ministério da Saúde tem publicado Boletins Epidemiológicos sobre a pandemia. O primeiro deles, de fevereiro desde ano, dava conta de uma pessoa infectada. Meses depois, o Boletim 18, de 13 de junho, informava a morte de 42.720 pessoas por COVID-19 e 64.247 por Síndrome Respiratória Aguda Grave (SAR-G). Esse Boletim 18 chama a atenção, por conter também informação sobre sinais de depressão na população brasileira. $41,70 \%$ das pessoas entrevistadas revelaram sinais de depressão. A informação não aparece nos boletins seguintes.

Laborare. Ano III, Número 5, Jul-Dez/2020, pp. 45-68. ISSN 2595-847X. https://revistalaborare.org/ DOI: https://doi.org/10.33637/2595-847x.2020-57 


\section{CONCLUSÃO}

Os números analisados nesse breve estudo não contemplam toda a realidade de adoecimento psicossocial em razão do trabalho, mas já permitem perceber com nitidez os efeitos nocivos do desmanche operado no Brasil e na Espanha, em relação às normas de proteção social, e sua influência na saúde psíquica de quem depende do trabalho para sobreviver. $\mathrm{O}$ fato de o mundo enfrentar uma pandemia, justamente em momento no qual a classe trabalhadora se vê desamparada por políticas de austeridade que concretamente pioram ou impedem as possibilidades de vida digna, revela um quadro assustador.

Para se ter uma ideia, de 2012 a 2018, somente o Brasil registrou 16.455 mortes e 4.5 milhões de acidentes de trabalho, o que acarretou o gasto de $\mathrm{R} \$ 79$ bilhões de gastos da Previdência Social com benefícios acidentários. No mundo, de acordo com as estatísticas da OIT, a cada 15 segundos, morre um (a) trabalhador (a) em virtude de um acidente de trabalho ou de doença relacionada com a sua atividade profissional, o que totaliza 6.300 mortes por dia num total de 2,3 milhões de mortes por ano. No que tange às doenças profissionais, são 313 milhões de trabalhadores e trabalhadoras sofrendo lesões profissionais não fatais todos os anos, ou seja, 860.000 pessoas feridas no trabalho todos os dias (OIT, 2020).

Quando analisamos "somente" os fatores de riscos psíquicos, não temos dúvidas que as "reformas" trabalhistas, ao precarizarem as condições materiais de trabalho e colaborarem para a degradação do meio ambiente laboral, aumentaram a incidência do estresse e da depressão, doenças que difícilmente são reconhecidas como relacionadas diretamente ao trabalho, e que podem ocasionar inúmeras outros transtornos, incluindo os distúrbios endócrinos, os cardiovasculares e musculoesqueléticos. Apesar de ser difícil a comprovação da relação com o trabalho, as estatísticas demonstram que não só as "reformas" trabalhistas potencializaram a ocorrência de acidentes e doenças relacionadas ao trabalho, como também pioraram a própria percepção que o trabalhador possui sobre o seu trabalho, o que, indiscutivelmente, contribui para o adoecimento psíquico.

Além do impacto inimaginável que tais doenças podem causar na saúde, nas relações familiares e sociais, podem também causar a perda das competências no trabalho, construídas ao longo do tempo, gerando a perda da produtividade para a empresa e o pagamento dos dias por afastamento, pelo Estado. A doença COVID-19, com tudo que dela decorre em termos de isolamento social e interrupção de atividades laborais, agrava um quadro social já adoecido. Inúmeras organizações, inclusive, estão emitindo alertas, seja no Brasil, seja na Espanha, para que as empresas tenham

Laborare. Ano III, Número 5, Jul-Dez/2020, pp. 45-68. ISSN 2595-847X. https://revistalaborare.org/ DOI: https://doi.org/10.33637/2595-847x.2020-57 
atenção com os fatores psicossociais de adoecimento de quem trabalha, e de seu agravamento em razão da pandemia.

A medida necessária, diante da constatação de que há um efeito social deletério que decorre diretamente da fragilização e supressão das normas de proteção social, é a reversão da lógica liberal que impregna as opções políticas adotadas nesses dois países nos últimos anos. Concretamente, é preciso rever legislações que suprimem direitos, fragilizam os vínculos e pioram a remuneração de quem vive do trabalho. Sem um trabalho decente, que dê condições materiais de vida digna, aí compreendidas as possibilidades de comer, vestir, morar e viver com conforto e com tempo livre, não há sociedade que se desenvolva, sequer da perspectiva econômica.

Há, portanto, um ensinamento que precisa ser aprendido com urgência nesses tempos estranhos. Viver bem em sociedade inclui a saúde psíquica. E a saúde psíquica, em uma sociedade de trocas, depende diretamente de vínculos seguros, salários decentes e ambientes saudáveis de trabalho.

Iniciamos o artigo fazendo referência à música "Cálice". Entendemos que não há como tragar a dor e engolir a labuta quando há um desemprego recorde no país e um estímulo à falsa autonomia, como se fosse essa a solução para o desemprego. Não há como concordar com a "gorda porca que já não anda" quando a desigualdade no país aumenta assustadoramente em razão das opções legislativas tomadas. Não há como permanecermos caladas quando a banalização da saúde e segurança no trabalho tem provocado adoecimento e morte.

O nosso grito é demasiadamente humano, pois assim como a maioria das brasileiras e brasileiros, carregamos a dor de mais de 140 mil mortos e 4 milhões de pessoas infectadas por uma doença que poderia e deveria ter sido combatida de modo diverso. Uma realidade que adoece quem tem um mínimo de empatia, quem segue precisando expor seus corpos, quem está em luto pela perda de pessoas próximas. Em tal contexto de flagelo, uma realidade menos morta passa necessariamente pela reversão das "reformas", pela adoção de políticas públicas que de algum modo previnam e combatam a disseminação do vírus e pela adoção de regras que minimizem, em vez de potencializar, o adoecimento psicossocial que decorre da desigual troca de trabalho por capital.

\section{NOTAS EXPLICATIVAS}

(1) Em 1984, a Organização Internacional do Trabalho (OIT), reconheceu que as rápidas mudanças tecnológicas vivenciadas no mundo do trabalho reduzem a qualidade e intensidade da energia física despendida no trabalho. Admitiu, também, a complexidade de definição dos fatores psicossociais de adoecimento no trabalho, que

Laborare. Ano III, Número 5, Jul-Dez/2020, pp. 45-68. ISSN 2595-847X. https://revistalaborare.org/ DOl: https://doi.org/10.33637/2595-847x.2020-57 
consistem, por um lado, em interações entre o trabalho, seu meio ambiente, a satisfação no trabalho e as condições de sua organização e, por outro lado, nas capacidades do trabalhador, suas necessidades, sua cultura e sua situação pessoal fora do trabalho, circunstâncias que podem influenciar na saúde e na vida de quem trabalha. Portanto, os fatores psicossociais não se relacionam somente com as doenças como estresse e depressão, mas também com doenças cardiovasculares ou musculares, vez que os riscos psicossociais estão estreitamente relacionados ao estresse laboral, desencadeador dessas doenças físicas (OIT, 1984).

(2) Sobre todos os aspectos negativos da terceirização, ver: J. L. Souto Maior, V. Severo. (Org.), Resistência III: 0 Direito do Trabalho diz não à Terceirização, Expressão Popular, São Paulo, 2019.

(3) A dualidade a qual nos referimos consiste em um alto índice de contratos temporários ao lado dos contratos indeterminados, sendo certo que esta realidade é um dos mais graves problemas de precariedade do mercado de trabalho espanhol. Os dados relativos ao 40 trimestre de 2019, divulgados pelo Ministério do Trabalho, Migrações e Seguridade Social, apontam que a taxa de temporalidade se encontrava em $26,1 \%$, permanecendo ainda bem superior ao restante da União Europeia, que se mantém na média dos $14 \%$, demonstrando que as "reformas" trabalhistas empreendidas em nada melhoraram a situação precária deste tipo de contrato.

(4) $O$ artigo 13 da LET sofreu algumas alterações. Se antes referia-se ao trabalho em domicílio passa a referir-se ao trabalho à distância, definindo o mesmo como aquele em que a prestação da atividade de trabalho seja realizada predominantemente na casa do trabalhador ou no local escolhido liuremente por ele, como alternativa ao seu desenvolvimento presencial no local de trabalho da empresa. Não há referência a quem caberá o pagamento dos custos decorrentes do trabalho à distância como internet e computador. Ao revés, o artigo dispõe que o trabalhador à distância terá os mesmos direitos do trabalhador que preste seus serviços no centro.

(5) A indenização das chamadas "demissões improcedentes" era paga no importe de 45 (quarenta e cinco) dias por ano até o máximo de 42 (quarenta e dois) pagamentos mensais, tendo sido reduzida para 0 pagamento de 33 (trinta e três) dias por ano até o pagamento de 24 (vinte e quatro) pagamentos mensais.

(6) Chamamos a atenção que, diferentemente do que ocorre no Brasil, a Espanha, tendo aderido à Convenção 158 da OIT, não permite a demissão sem justa causa para os contratos indeterminados, salvo nas possibilidades previstas no artigo 52 da LET. Caso o trabalhador entenda que a sua demissão se deu injustificadamente, poderá ingressar no judiciário e pedir que seja reconhecida como improcedente. 0 empresário também poderá reconhecê-la. Se reconhecida pelo Poder Judiciário, o empregador poderá reintegrá-lo ao trabalho ou pagar uma indenização.

(7) Chamamos a atenção para o artigo 47 da LET posto que, na Espanha, já era prevista a possibilidade de suspensão dos contratos de trabalho nas hipóteses explicitadas, o que será utilizado no período da pandemia do Covid-19. Todavia, antes da reforma de 2012, o artigo mencionava que "a autorização desta medida prosseguirá quando constar da documentação que essa medida temporária é necessária para superar uma situação de natureza conjuntural da atividade da empresa". Após a Reforma, o artigo regulamenta as hipóteses cabíveis, incluindo o que entende como causa econômica passível de suspender os contratos e passa a permitir a redução da jornada A jornada de trabalho pode ser reduzida por razões econômicas, técnicas, organizacionais ou de produção, de acordo com o procedimento estabelecido na LET, admitindo-se a redução temporária de 10 a 70\% da jornada calculada com base na jornada diária, semanal, mensal ou anual. Estabelece, ainda, que, durante o período de suspensão ou redução de jornada, deverá haver o desenvolvimento de ações de treinamento vinculadas à atividade profissional dos trabalhadores afetados, cujo objetivo é aumentar sua versatilidade ou aumentar sua empregabilidade.

(8) Chamamos a atenção que a Espanha utiliza a expressão "estado de alarma", que entendemos ser semelhante ao estado de emergência. Segundo o disposto no artigo 4ㅇ da Lei Orgânica 4/1981, o Governo, conforme o artigo 116.2 da Constituição Espanhola, poderá declarar o "estado de alarma" quando ocorra alguma alteração grave da normalidade, sendo um exemplo desta a crise sanitária, tal como epidemia e situação de contaminação grave.

Laborare. Ano III, Número 5, Jul-Dez/2020, pp. 45-68. ISSN 2595-847X. https://revistalaborare.org/ DOI: https://doi.org/10.33637/2595-847x.2020-57 
(9) Ressalta-se que, diferente do Brasil, os autônomos possuem um regime próprio de previdência social na Espanha. $O$ valor a que faz jus receber equivale a $70 \%$ da sua contribuição caso tenha o mínimo de 12 (doze) contribuições mensais. Caso não tenha, será o equivalente a $70 \%$ da base mínima, o que significa dizer que receberá 661 euros.

\section{REFERÊNCIAS}

ADASCALITEI, Dragos; MORANO, Clemente Pignatti. Labour market reforms since the crisis: Drivers and consequences. International Labour Office, 2015.

AFFOR PREVENCIÓN PSICOSOCIAL. Impacto Del COVID-19 en la Salud Psicológica de lós Trabajadores en España 1. 2020. Disponível em: https://affor.es/ el-42-de-la-poblacion-trabajadora-encuestada-presenta-sintomas-de-ansiedad/. Acesso em: agosto de 2020.

AGÊNCIA BRASIL. CHAGAS, Paulo Victor. Transtornos mentais são a terceira maior causa de afastamento do trabalho. 26.04.2017. Disponível em: https://agenciabrasil.ebc.com.br/geral/noticia/2017-04/transtornos-mentais-saoterceira-maior-causa-de-afastamento-do-trabalho. Acesso em: julho de 2020.

BRASIL. Ministério da Fazenda. Instituto Nacional de Seguro Social. Anuário Estatístico de Acidentes de Trabalho 2017. 997p. Disponível em: http://sa.previdencia.gov.br/site/2018/09/AEAT-2017.pdf. Acesso em: julho de 2020.

. Ministério da Saúde. Fiocruz. Saúde Mental e Atenção Psicossocial na

Pandemia COVID-19 - Recomendações Gerais. 2020. 8 p. Disponível em https://www.fiocruzbrasilia.fiocruz.br/wp-content/uploads/2020/04/Sa\%c3\%badeMental-e-Aten\%c3\%a7\%c3\%a3o-Psicossocial-na-Pandemia-Covid-19-recomenda $\%$ c3\%a7\%c3\%b5es-gerais.pdf. Acesso em: agosto de 2020.

Ministério Público do Trabalho. Observatório de Saúde e Segurança no Trabalho. 2020. N.p. Disponível em: https://smartlabbr.org/sst/localidade/0? dimensao=frequenciaAcidentes. Acesso em: agosto de 2020.

. Ministério Público do Trabalho. Observatório de Saúde e Segurança no Trabalho. 2020. N.p. Disponível em: https://smartlabbr.org/sst/localidade/0? dimensao=perfilCasosAfastamentos. Acesso em: agosto de 2020.

- Organização das Nações Unidas. 2020. N.p. Disponível em https://nacoesunidas.org/oms-o-impacto-da-pandemia-na-saude-mental-das-pessoasja-e-extremamente-preocupante/. Acesso em: agosto de 2020.

Tribunal Superior do Trabalho. 2019. Disponível em: http://www.tst.jus.br/web/trabalhoseguro/programa/-/asset_publisher/0SUp/content/

Laborare. Ano III, Número 5, Jul-Dez/2020, pp. 45-68. ISSN 2595-847X. https://revistalaborare.org/ DOI: https://doi.org/10.33637/2595-847x.2020-57 
justica-do-trabalho-do-ceara-promove-campanha-para-prevenir-acidentes-detrabalho. Acesso em: agosto de 2020.

CONSELHO REGIONAL DE PSICOLOGIA DO PARANÁ. 2020. O sofrimento psíquico das(os) trabalhadoras(es) em tempos de pandemia. 01.05.2020. N.p. Disponível em: https://crppr.org.br/1demaio/. Acesso em: agosto de 2020.

ESPANHA. Instituto Nacional de Seguridad y Salud en el Trabajo. Informe sobre el estado de la seguridad y salud laboral en España. 2011. Madrid, marzo de 2013. 164 pp.

Disponível

em: https://www.insst.es/documents/94886/618461/Informe+sobre+el+estado+de+la+seg uridad $+\mathrm{y}+$ salud+laboral+en+Espa\%C3\%B1a+2011/58e1c93e-dbb4-4edf-bc3f9b22e3336805. Acesso em: julho de 2020.

. Instituto Nacional de Seguridad y Salud en el Trabajo. Informe sobre el estado de la seguridad y salud laboral en España. 2018. Madrid, marzo de 2020. $144 \mathrm{p}$. Disponível em: https://www.insst.es/documents/94886/618461/Informe+sobre+el+estado+de+la+seg uridad+y+salud+laboral+Espa\%C3\%B1a+2018.pdf/be095b10-aa95-4c69-9908e163784312a9. Acesso em: julho de 2020.

. Instituto Nacional de Seguridad y Salud en el Trabajo. Ministerio del trabajo y Economía Social. VII Encuesta Nacional de Condiciones de Trabajo-2011. 57p. Disponível em: https://www.insst.es/documentacion/catalogo-de-publicaciones/viiencuesta-nacional-de-condiciones-de-trabajo-2011. Acesso em: julho de 2020.

. Instituto Nacional de Seguridad y Salud en el Trabajo. Ministerio del trabajo y Economía Social Encuesta Nacional de Condiciones de Trabajo - $6^{\mathrm{a}}$ EWCS. Madrid, Marzo de 2017. 154p. Disponível em: https://www.insst.es/documents/94886/96082/Encuesta+Nacional+de+Condiciones+ de+Trabajo+6\%C2\%AA+EWCS/abd69b73-23ed-4c7f-bf8f-6b46f1998b45. Acesso em julho de 2020.

Ministerio de la Presidencia, Relaciones con las cortes y memoria democratica. Agencia Estatal Boletín Oficial. Estatuto de los trabajadores 2010. N.p. Disponível em: https://www.boe.es/buscar/doc.php?id=BOE-A-2010-9542. Acesso em: julho de 2020.

- Ministerio de la Presidencia, Relaciones con las cortes y memoria democratica. Agencia Estatal Boletín Oficial. Estatuto de los trabajadores 2012. N.p. Disponível em: https://www.boe.es/buscar/doc.php?id=BOE-A-2012-2076. Acesso em: julho de 2020.

Ministerio de la Presidencia, Relaciones con las cortes y memoria democratica. Agencia Estatal Boletín Oficial. Covid-19: Derecho europeo, estatal y

Laborare. Ano III, Número 5, Jul-Dez/2020, pp. 45-68. ISSN 2595-847X. https://revistalaborare.org/ DOI: https://doi.org/10.33637/2595-847x.2020-57 
autonómico. 2020. 1968 pp. Disponível em: file://C:/Users/ipbar/Downloads/BOE355_COVID-19_Derecho_Europeo_Estatal_y_Autonomico_compressed.pdf. Acesso em: julho de 2020.

. Ministerio de Trabajo e Economía Social. Estadística de Accidentes de Trabajo 2019. Resumen de principales resultados. 2019. 5pp. Disponível em: http://www.mites.gob.es/estadisticas/eat/eat19/TABLAS\%20ESTADISTICAS/ ATR_2019_Resumen.pdf, Acesso em: julho de 2020.

FISCHER, Frida Marina. Relevância dos fatores psicossociais do trabalho na saúde do trabalhador. Revista de Saúde Pública, v. 46, n. 3, p. 401-406, 2012.

INSTITUTO BRASILEIRO DE GEOGRAFIA E ESTATÍSTICA. Pesquisa Nacional por Amostra de Domicílios Contínua. 2020. Disponível em: https://www.ibge.gov.br/ estatisticas/sociais/trabalho/17270-pnad-continua.html. Acesso em: julho de 2020.

. PNAD Contínua 2019: rendimento do $1 \%$ que ganha mais equivale a 33,7 vezes o da metade da população que ganha menos. 06/05/2020. Disponível em https://agenciadenoticias.ibge.gov.br/agencia-sala-de-imprensa/2013-agencia-denoticias/releases/27594-pnad-continua-2019-rendimento-do-1-que-ganha-maisequivale-a-33-7-vezes-o-da-metade-da-populacao-que-ganha-menos. Acesso em: julho de 2020.

INSTITUTO NACIONAL DE ESTADÍSTICA. Encuesta de Condiciones de Vida. 2019. N.p. Disponível em: https://www.ine.es/dyngs/INEbase/es/operacion.htm? $\mathrm{c}=$ Estadistica_C\&cid $=1254736176807 \& \mathrm{menu}=$ ultiDatos\&idp $=1254735976608$. Acesso em: julho de 2020.

. Encuesta Nacional de Poblácion Activa. Cuarto Trimestre de 2019.

27pp. 28 de janeiro de 2020. Disponível em:
https://ine.es/daco/daco42/daco4211/epa0419.pdf. Acesso em julho de 2020.

. Encuesta Nacional de Poblácion Activa. Segundo Trimestre de 2020. 35pp. 28 de julho de 2020. Disponível em: https://www.ine.es/daco/daco42/daco4211/epa0220.pdf. Acesso em: agosto de 2020.

. Indicador de Confianza Empresarial. 2020. 17pp. Disponível em: https:// www.ine.es/daco/daco42/ice/ice_mod_covid_0320.pdf. Acesso em: agosto de 2020.

OBSERVATÓRIO DO $3^{\circ}$ SETOR. Como a pandemia impacta a saúde mental dos profissionais que atuam em hospitais. 01/04/2020. N.p. Disponível em: https://observatorio3setor.org.br/noticias/pandemia-e-a-saude-mental-profissionaishospitais/. Acesso em: agosto de 2020.

ORGANIZAÇÃO DAS NAÇÕES UNIDAS. Policy Brief: COVID-19 and the need for action mental health. 2020. N.p. Disponível em:

Laborare. Ano III, Número 5, Jul-Dez/2020, pp. 45-68. ISSN 2595-847X. https://revistalaborare.org/ DOI: https://doi.org/10.33637/2595-847x.2020-57 
https://www.un.org/sites/un2.un.org/files/un_policy_brief-

covid_and_mental_health_final.pdf. Acesso em: agosto de 2020.

ORGANIZAÇÃO INTERNACIONAL DO TRABALHO. Segurança e Saúde no Trabalho. Disponível em: https://www.ilo.org/lisbon/temas/WCMS_650864/lang-pt/index.htm. Acesso em: agosto de 2020.

. World Employment Social Outlook. Trends 2019. 2019. 122p. Disponível em: $\quad$ https://www.ilo.org/wcmsp5/groups/public/---dgreports/---dcomm/---publ/ documents/publication/wcms_670542.pdf. Acesso em: julho de 2020.

ORGANIZAÇÃO MUNDIAL DA SAÚDE. Datos estadísticos. 2016. Disponível em: https://www.who.int/countries/bra/es/. Acesso em: agosto de 2020.

. Depression and other common Mental Disorders. Global health

estimates. $2017.24 \quad$ p. 24 Disponível em:

https://apps.who.int/iris/bitstream/handle/10665/254610/WHO-MSD-MER-2017.2-

eng.pdf;jsessionid=8898C0A87E5F3DE61088E434498BDF10?sequence=1. Acesso em: agosto de 2020.

ORGANIZAÇÃO PAN-AMERICANA DE SAÚDE. Proteção da Saúde Mental em situações de epidemia. 2009, 24p. Disponível em: https:/www.paho.org/hq/dmdocuments/2009/Protecao-da-Saude-Mental-emSituaciones-de-Epidemias--Portugues.pdf. Acesso em agosto de 2020.

ORGANIZAÇÃO PARA A COOPERAÇÃO E DESENVOLVIMENTO ECONÔMICO. OECD Employment Outlook 2020. N.p. 2020. Disponível em: https://www.oecd-ilibrary.org/sites/1686c758-en/index.html?itemId=/content/ publication/1686c758-en. Acesso em julho de 2020.

Recebido: $27 / 08 / 2020$

Revisado: 08/09/2020

Aprovado: 13/09/2020

Laborare. Ano III, Número 5, Jul-Dez/2020, pp. 45-68. ISSN 2595-847X. https://revistalaborare.org/ DOI: https://doi.org/10.33637/2595-847x.2020-57 